\title{
The Use of an Aeration System to Prevent Thermal Stratification of Water Bodies: Pond, Lake and Water Supply Reservoir
}

\author{
Md. Saidul Azam Chowdhury*, Khairul Hasan, Kaosar Alam \\ Department of Civil and Environmental Engineering, Shahjalal University of Science and Technology, Sylhet, Bangladesh \\ *Corresponding author: tuhin_st7@yahoo.com
}

Received November 15, 2013; Revised November 29, 2013; Accepted January 02, 2014

\begin{abstract}
Water bodies such as lakes, ponds or water supply reservoir show vertical stratification of their masses, at least for some extended time periods. Density differences facilitate the process of stratification. Temperature and dissolved substances contribute to density differences in water. As a result, thermal stratification can be established during the warm season if the water bodies are sufficiently deep. On the contrary, during the cold season surface cooling force the vertical circulation of water as a result turnover will occur. In warmer weather regions such as Bangladesh, India etc. this annual cycle spending more time in late summer and early fall. Thermal stratification is a common phenomenon here. Failure to identify and control, stratification, can cause low oxygen level, fish die-offs, excessive growth of plankton, failure of meeting regulatory standards, customers' expectations. So, identify the early onset of stratification and developed operational response procedures that introduce appropriate control measures such as aeration to avoid potential impacts and minimize any adverse effects.
\end{abstract}

Keywords: thermal stratification, aeration system, destartification system, epilimnium, hypolimnium, thermocline

Cite This Article: Md. Saidul Azam Chowdhury, Khairul Hasan, and Kaosar Alam, “The Use of an Aeration System to Prevent Thermal Stratification of Water Bodies: Pond, Lake and Water Supply Reservoir.” Applied Ecology and Environmental Sciences 2, no. 1 (2014): 1-7. doi: 10.12691/aees-2-1-1.

\section{Introduction}

Humanity needs to be prepared for the changes it imposes upon the Earth, especially in times of global change and of direct human impact on the hydrological cycle. The anthropogenic impact of the last decades on our aquatic environment has shown that a responsible use of our natural resources is mandatory to guarantee sustainable conditions [2]. Stratification is a natural occurrence, in any static body of water. It occurs when the surface layer of water, warmed by the sun, becomes less dense than the water underneath it. The development of layers within the profile of a water body is a common phenomenon of stratification [9]. Without intervention, the severity of stratification commonly increases, along with the possibility of drawing poor quality water from a storage reservoir as well as lower level of dissolved oxygen, excessive growth of algae.

To avoid these problems, the widely used tool is aeration. The purpose of aeration in lake management is to increase the dissolved oxygen content of the water and Aeration can also increase fish and other aquatic animal habitat, prevent fish kills and improve the quality of domestic and industrial water supplies and decrease treatment cost [13]. In some cases, nuisance algae blooms can be reduced. Again, aeration of lakes and reservoirs has been used for a number of years as a method of improving water quality. Aeration can be used for improvement of drinking water supplies, providing enhanced fisheries habitat and treatment of symptoms of eutrophication.

\section{Water Bodies}

In last few years the demand of water supply for agriculture, livestock and fish production has increased tremendously whereas ponds, lakes and water supply reservoirs are the reliable source of water to fulfill the demand.

Aeration can be arbitrarily divided into two basic categories. Destartification systems, as the name implies, uses compressed air to cause vertical water movement and mixing of the lake water column. Hypolimentic systems add oxygen to the lake without destroying the thermal stratification [6].

The term lake collectively refers to reservoirs (manmade impoundments), natural lake systems and smaller ponds (man-made or naturally created) Water from the surrounding watershed enters a pond or lake as stream flow, surface runoff and groundwater.

\subsection{Lake}

A lake could be a body of comparatively still water of considerable size, localized in an exceedingly basin, that's enclosed by land with the exception of a watercourse, 
stream, or alternative variety of moving water that serves to feed or drain the lake. Water temperatures in lakes throughout summer months aren't uniform from high to bottom. 3 distinct layers develop: the highest layer stays heat at around 65-75 degrees F (18.8-24.5 degrees $\mathrm{C}$ ). The center layer drops dramatically, typically to 45-65 degrees F (7.4-18.8 degrees C). Very cheap layer is that the coldest, staying at around 39-45 degrees $F$ (4.0-7.4 degrees C). Since light-weight doesn't penetrate to very cheap, chemical process is proscribed to the highest layer. Attributable to the hotter waters and additional plentiful food provide the majority creatures pay the summer months within the higher layer. During spring and fall the lake temperature is additional uniform. Fish and alternative animals' are found throughout the layers of the lake.

\subsubsection{Biological Zones}

Lakes contain several distinct zones of biological activity, largely determined by the availability of light and oxygen. The most important biological zones are the euphotic, littoral and benthic zones [3].

\section{Euphotic zone}

The Upper layer of water through which sunlight can penetrate is called euphotic zone. All plant growth occurs in this zone. In deep water, algae are the most important plants, while rooted plants grow in shallow water near the shore. The depth of euphotic zone is determined by the amount of turbidity blocking sunlight penetration. In most lakes, the turbidity is due to algal growth, although color and suspended clays may substantially reduce sunlight penetration in some lakes. In the euphotic zone, plants produce more oxygen by photosynthesis than they remove by respiration. Below the euphotic zone lies the profundal zone. The transition between the two zones is called the light compensation level. The light compensation level corresponds roughly to a depth at which the light intensity is about one percent of unattenuated sunlight. It is important to note that the bottom of the euphotic zone only rarely coincides with the thermocline.

\section{Littoral zone}

The shallow water near the shore in which rooted water plants can grow is called littoral zone. The extent of the littoral zone depends on the slope of the lake bottom and the depth of the euphotic zone. The littoral zone cannot extend deeper than the euphotic zone.

\section{Benthic zone}

The bottom sediments comprise the benthic zone. As organisms living in the overlying water die, they settle to the bottom where they are decomposed by organisms living in the benthic zone. Bacteria are always present. The presence of higher life forms such as worms, insects and crustaceans depends on the availability of oxygen.

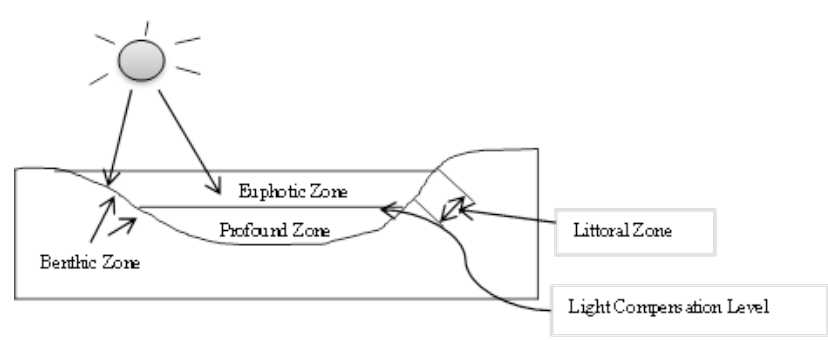

Figure 1. Biological zones in a lake

\subsubsection{Classification of Lake Based on Stratification}

The thermal characteristics of lakes are a result of climatic conditions that provide a useful physical classification which is based upon the stratification and mixing characteristics of the water bodies. Reference [5] classified lakes as follows:

\section{Dimictic lakes}

Occur in the cool temperate latitudes. Overturn occurs twice a year, normally in the spring and autumn. Heating in the spring results in stratification with a warm water epilimnion during the summer. The autumn overturn results in homothermal conditions (at approximately $4^{\circ} \mathrm{C}$ ) which then cool to create a cold water inverse stratification during the winter months. Spring warming results in mixing and a re-establishment of the annual cycle. The stratification and mixing processes for a large dimictic lake are illustrated in Figure. This type of lake is the most common form of lake. Since the cool temperate latitudes encompass most of the world's industrial nations they have been subjected to the most intensive study and represent the greatest part of our limnological knowledge.

\section{Cold monomictic lakes}

Occur in cold areas and at high altitudes (sub-polar). The water temperature never exceeds $4^{\circ} \mathrm{C}$ and they have a vertical temperature profile close to, or slightly below, $4^{\circ} \mathrm{C}$. They have winter stratification with a cold water epilimnion, often with ice cover for most of the year, and mixing occurs only once after ice melt.

\section{Warm monomictic lakes}

Occur in temperate latitudes in subtropical mountains and in areas strongly influenced by oceanic climates. In the same way as their cold water counterparts, they mix only once during the year with temperatures that never falls below $4^{\circ} \mathrm{C}$.

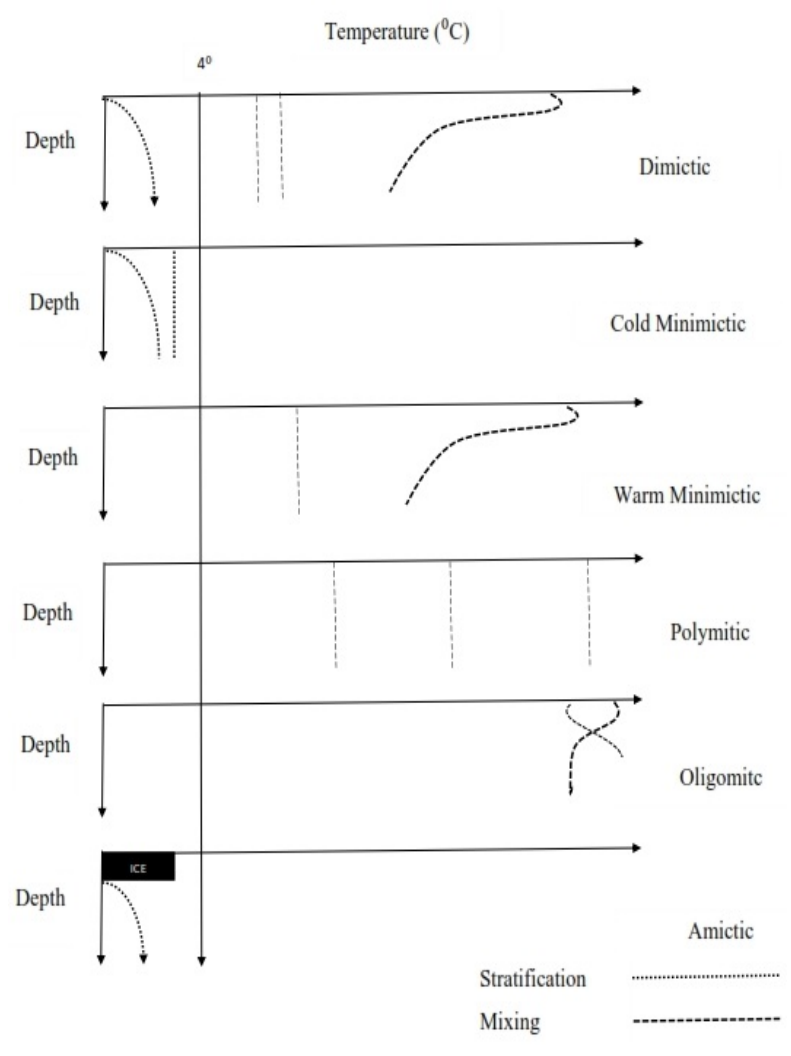

Figure 2. Lake thermal structure and classification based on mixing characteristics [5] 


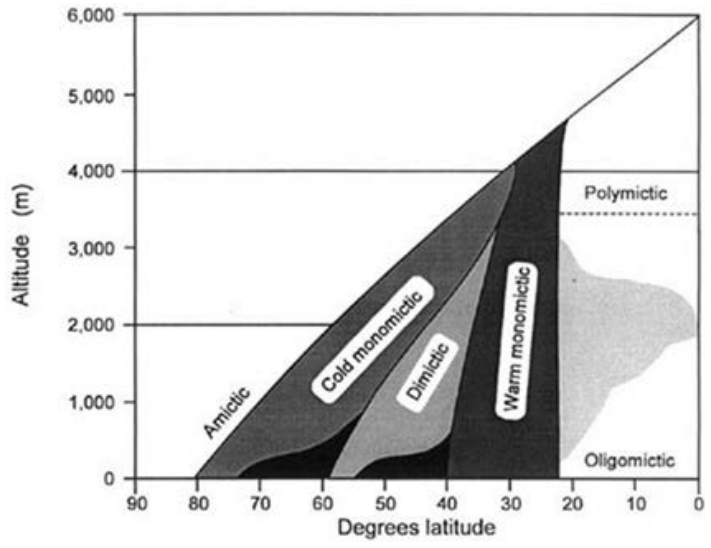

Figure 3. The global distribution of thermal lake types in relation to latitude and altitude [12]

\section{Polymictic lakes}

Occur in regions of low seasonal temperature variations, subject to rapidly alternating winds and often with large daily (diurnal) temperature variations. These lakes have frequent periods of circulation and mixing and may be subdivided into cold polymictic, which circulate at temperatures close to $4^{\circ} \mathrm{C}$, and warm polymictic which circulate at higher temperatures. As defined above, all shallow lakes fall within this category.

\section{Oligomictic lakes}

Occur in tropical regions and are characterized by rare, or irregular, mixing with water temperatures well above $4^{\circ} \mathrm{C}$.

\section{Amictic lakes}

Occur in the Polar Regions and at high altitudes. They are always frozen and never circulate or mix. Waters beneath the ice are generally at, or below, $4^{\circ} \mathrm{C}$ depending on the amount of heat generated from the lake bed or by solar radiation through the ice. These lakes show inverse cold water stratification.

\subsection{Pond}

In general, a pond could be a body of standing water, either natural or semisynthetic, that's typically smaller than a lake. Wet ponds accommodate a permanent pool of standing water that promotes a stronger atmosphere for gravitate sinking, biological uptake and microbe activity. Runoff from every new storm enters the lake and partly displaces pool water from previous storms. Water temperature is fairly even from high to bottom and changes with air temperature. There's very little wave action and also the bottom is typically coated with mud. Plants can, and sometimes do, grow on the pool edge. The number of dissolved element could vary greatly throughout every day. In extremely cold places, the complete pool will freeze solid.

The water quality of the surface waters of the state, as well as all lakes and ponds, is regulated through statutes (RSA 485-A) and rules (Env-Ws 1700). These laws and laws create no distinction between lakes and ponds. Each ought to meet all an equivalent water quality standards.

In earth science (the study of midland waters), surface waters are divided into lotic (waters that flow in a very continuous and definite direction) and lentic (waters that don't flow in a very continuous and definite direction) environments. Waters within the lentic category gradually fill in over geologic time and the evolution is from lake to pond to wetland. This evolution is slow and gradual, and there is no precise definition of the transition from one to the next.

\subsection{Reservoir}

A reservoir is a natural or artificial lake, storage pond or impoundment from a dam which is used to store water. Reservoirs may be created in river valleys by the construction of a dam or may be built by excavation in the ground or by conventional construction techniques such as brickwork or cast concrete.

\section{Thermal Stratification}

The thermal stratification of lakes, ponds or reservoirs refers to a change in the temperature at different depths, and is due to the change in water's density with temperature. Anyone who has taken a summer swim and gone through the warm surface water to feel the icy water a few feet underneath, has felt the most obvious effect of thermal stratification.

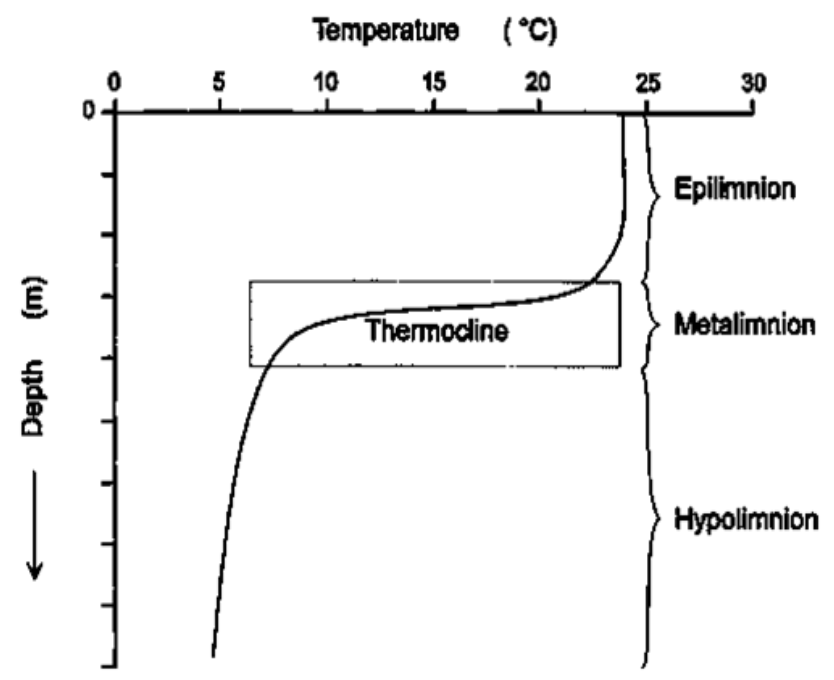

Figure 4. Typical temperature profile from a stratified lake in the temperate zone, showing the division of the water into three layers of different density

The surface layer remains on top and the lower layer, deprived of surface contact and insulated from the sun, continues to get colder. This increases the difference in density between the two layers and makes it even more difficult for them to mix together. Once strongly established, this stratification persists until falling temperatures in autumn breaks down the density difference between the two layers allowing them to mix together again.

The significance of thermal stratification to anglers is that the lower layer of water, deprived of surface contact, slowly loses its dissolved oxygen and become less able to support aquatic life. In deep lakes and reservoirs, this has the effect of confining Cold water species, like trout, to a narrow zone below the high temperature surface water but above the bottom layer of cold water lacking oxygen. A good echo sounder will sometimes show this prominent layer of fish, with nowhere to go and very little to eat, and the angler who can accurately get a lure or bait into this "fish zone" can be extremely successful. 


\subsection{Basic Characteristics of Stratification}

Thermal Stratification is a term meaning temperature layering. Some of the important features of stratification are:

- A layer of aerobic water, near the surface, known as the epilimnium, that is relatively warm and high in dissolved oxygen (commonly above $7 \mathrm{ppm}$ ). In this zone, temperature and dissolved oxygen (D.O.) levels tend to be maintained by the penetration of sunlight and mixing created by wind [9].

- A layer of water, known as the hypolimnium, that is commonly anaerobic, extends from the bottom of the reservoir and is relatively cool and low in dissolved oxygen (commonly below 3 ppm) [3].

- A very thin layer of water, known as the thermocline, where a rapid change in temperature and dissolved oxygen occurs in between the epilimnium and hypolimnium.

- Stratification becomes more severe during warmer months when the intensity and duration of sunlight increases, and mixing from reservoir inflow decreases due to reductions in stream flow [9]. As the severity of stratification increases, the contrast in water temperature and D.O. between the epilimnium and hypolimnium tends to become more pronounced, and the position of the thermocline tends to rise, effectively increasing the proportion of the hypolimnium.

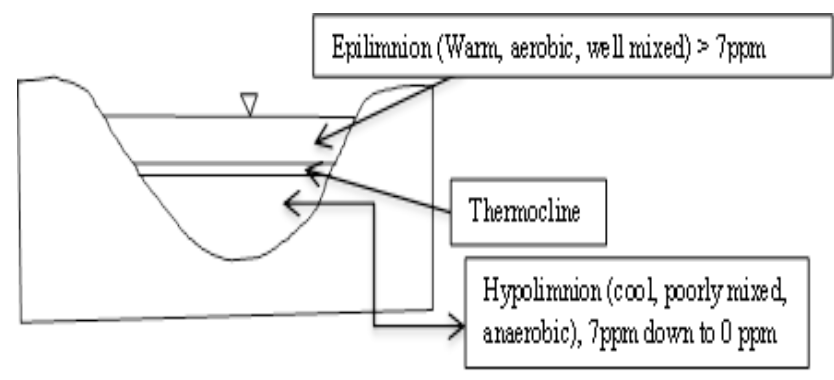

Figure 5. Stratification during summer

\subsection{Seasonal Cycle of Thermal Stratification}

During the summer, the surface water of a lake is heated both indirectly by contact with warm air and directly by sunlight. Warm water, being less dense than cool water, remains near the surface until mixed downward by turbulence from wind, waves, boats or other forces. Because this turbulence extends only a limited distance, the result is an upper layer of well-mixed, warm water floating on the lower water, which is poorly mixed and cool. Because of good mixing the epilimion will be aerobic. The hypolimnion will have a lower DO and may become anaerobic. The boundary is called the thermocline because of the sharp temperature change that occurs within a relatively short distance. The depth of the epilimnion is related to the size of the lake. It is as little as one meter in small lakes and as much as 20 meters or more in large lakes. The depth of the epilimnion is also related to storm activity in the spring when stratified is developing. A major at the right time will mix warmed water to a substantial depth and thus create a deeper than normal epilimnion. Once formed, stratification is very stable. It can be broken only by exceedingly violent storms. In fact, as the summer progresses, the stability increase because the epilimnion continues to warm, while the hypolimnion remains at a fairly constant temperature.

In the fall, as temperatures drop, the epilimnion cools until it is denser than the hypolimnion. The surface water then sinks, causing overturning. The water of the hypolimnion rises to the surface where it cools and again sinks. The lake thus completely mixed. If the lake is in a cold climate, this process stops when the temperature reaches $4^{\circ} \mathrm{C}$, since this is the temperature at which water is most dense. Further cooling or freezing of the surface water results in winter stratification. As the water warms in the spring, it again overturns and becomes completely mixed.

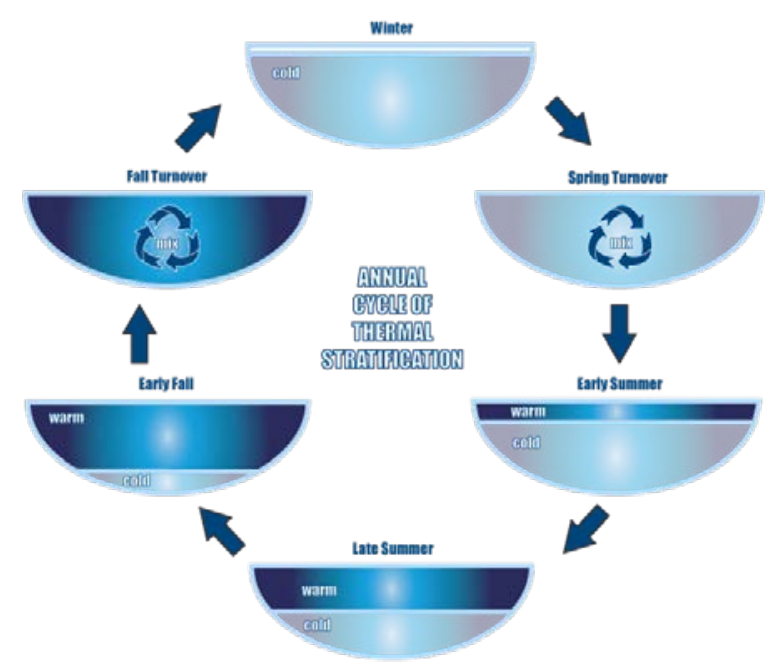

Figure 6. Seasonal cycle and turnover of thermal stratification

\subsection{Factors That Affects Turnover}

Wind, Solar radiation input, Depth, Air temperature, Lake or pond size, Lake or pond bottom topography, Streams entering lake or pond etc. are the main factors that affects turnover.

As Thermal stratification occurs in a seasonal cycle with the thermocline becoming more severe in late summer and late winter. Lakes and ponds in warmer weather regions experience a shorter annual cycle spending more time in late summer and early fall conditions.

\subsection{Problems related to stratification [4]}

- Fish kills: The spatial distribution of fish within a lake is often adversely affected by thermal stratification and in some cases may indirectly cause large die-offs of recreationally important fish.

- Foul odors: As result of the release of hydrogen sulphide.

- Low oxygen level: For most ponds or lakes, oxygen production is limited to wind diffusion, wave action and photosynthesis, which often leads to dangerously low dissolved oxygen levels, thermal stratification and stagnation.

- Weed growth: Excessive amounts of aquatic weeds throughout the water column can affect the balance of the lake or pond's ecosystem and also interferes with recreational activities such as swimming, fishing, boating and irrigation. Unchecked, nuisance 
aquatic vegetation can also cause water quality issues, fish die offs, foul odors and an unsightly appearance.

- Algae growth: Algae feeds on nutrients in the water that are released from decaying matter such as fallen leaves, grass clippings, fish waste, uneaten fish food, dead bugs, dead aquatic vegetation, as well as phosphorous and nitrogen that washes into the pond from the surrounding land. Large growth of algae can lowering the depth of the lake as well as the further use if it.

\subsection{Potential Effects of Stratification on Urban Water Authorities}

One of the common causes of problems to water resource operations is that the thermocline rises above the designated off take level and water of poor quality is drawn from the reservoir. Some of the most common problems that can be associated with reservoir stratification [9] are outlined below:

- Water treatment processes can become difficult to manage and the cost of treatment can increase substantially.

- The ability to meet regulatory standards in regard to drinking water quality can become compromised.

- Water odor can become a problem, particularly as a result of the release of hydrogen - sulphide.

- Manganese and iron particles can become prevalent in anaerobic water. If these particles are not detected during treatment, clothing items can become stained during washing as these particles react with the oxygen particles I washing detergent.

- The likelihood of receiving customer complaints can increase.

- Adverse effects on the ecosystem within the reservoir can occur as a result of the formation of minerals due to low D.O. levels, potential impacts on aquatic life such as fish kills and the potential for algal blooms to occur may also increase.

In extreme cases, a severely stratified reservoir may potentially need to be isolated from a water supply system due to poor water quality.

\section{Introducing Stratification Control Measures}

A healthy pond is all about nutrient and oxygen balance [7]. The level of oxygen and how it is distributed throughout the water column is one of the keys to pond health. Oxygen in a pond comes from two natural sources - diffusion from the air and, most importantly, as a byproduct of photosynthesis. An imbalance of oxygen occurs during the night, overcast days, ice/snow cover when no sunlight is present and photosynthesis cannot occur. Temperature also has a major impact on a pond's balance of oxygen. As the temperature increases, thermal stratification - the difference in temperature at different depths of water - starts to occur.

An aeration system allows you to supplement the actions of nature by adding a supply of diffused oxygen. The use of aeration as a control measure can be very effective to reduce stratification. Aeration would normally be accomplished for the following purpose [7]:
- Aeration to limit the growth of algae and minimize algae concentrations in the pond.

- Increase the Dissolved Oxygen (D.O.) level in the basins in order to allow fish propagation.

- Increase D.O. levels in the basin to eliminate odors and gasses escaping from the benthal (sludge) deposits.

For ponds or lakes which are very deep, there can be a need for destartification.

\subsection{Destartification Systems}

Destratification is a type of artificial circulation that completely mixes a stratified lake's waters from top to bottom and thereby eliminates or prevents summer stratification [6] (the division of a lake into water layers of different temperatures).

It is possible to provide the required oxygen in situ by artificially mixing the lake or water bodies. It has been shown [11] that the primary mechanism of oxygen transfer is at the water surface even if compressed air is used as mixing device. Riddick [10] concluded that "an aerator should be regarded as a cheap, uncomplicated and relatively efficient device for pumping water".

Two techniques [13] are most common: air injection and mechanical mixing.

- Air Injection (Diffuser) systems are the most common destartification method. A compressor on shore delivers air through lines connected to a perforated pipe(s) or other simple diffuser(s) placed near the bottom, typically in the deep area of the lake. The rising air bubbles cause water in the hypolimnion to also rise, pulling this water into the epilimnion. When the colder, hypolimnion water reaches the lake surface; it flows across the surface and eventually sinks, mixing with the warmer epilimentic water. Evebtually, the entire lake becomes of nearly equal temperature with oxygen distributed throughout. This aeration technique is sometimes referred to as the air-lift method of circulation.

- Mechanical axial flow pumps use a "top-down" approach to set up a circulation pattern. A floatation platform and frame support an electric motor, gearbox, drive shaft and large propeller (6-15 feet diameter). Its rotation pushes water from the lake surface downward, setting up a circulation pattern that prevents thermal stratification.

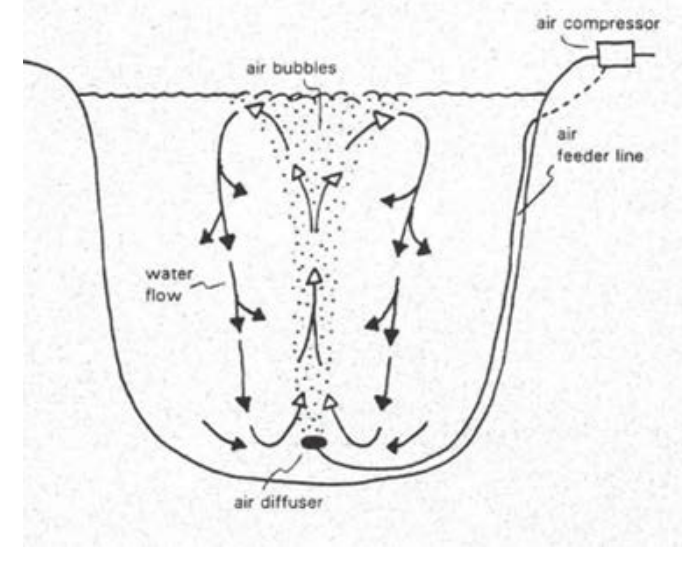

Figure 7. Air injection system 


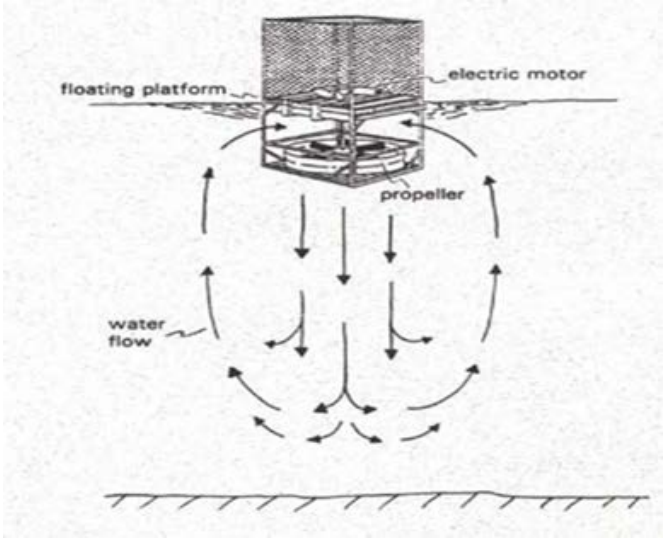

Figure 8. Mechanical axial flow pumps

\section{Other systems}

Reference [13] proposed other systems as follows:

- Surface spray units consist of a float supporting an electric motor-driven impeller. The rapidly-turning impeller pulls water up a vertical tube and throws it out in an umbrella or fountain shaped spray a few to many feet above the lake surface. Atmospheric reaeration occurs in the sprayed water and at the agitated lake surface.

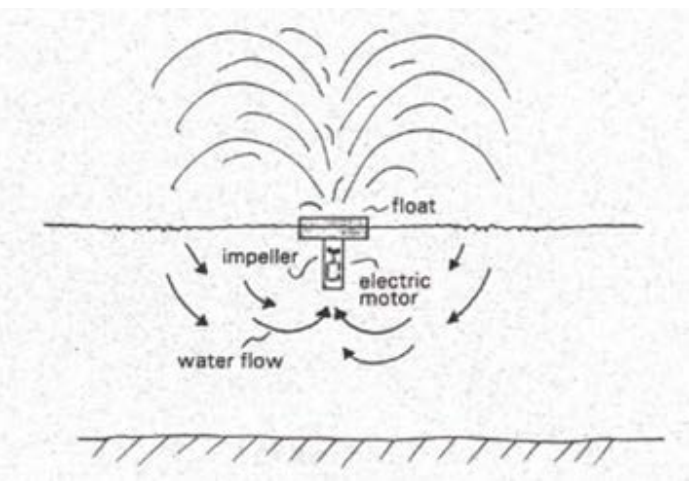

Figure 9. surface Spray

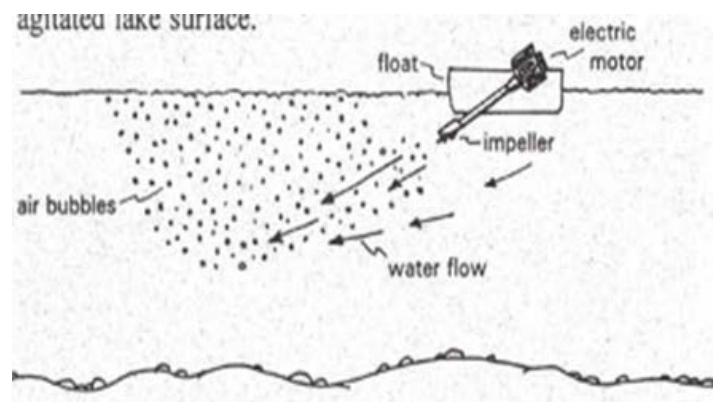

Figure 10. Impeller-Aspirator systems

- Impeller-Aspirator systems consist of an electric motor-driven impeller at the bottom of a hollow shaft extending at an angle down into the water. The assembly floats on the lake surface. The rapidly turning impeller draws air down the shaft and propels water and air bubbles into the lake. Aeration takes place through air bubble and at the agitated lake surface.

- Pump and Cascade system consists of a large pump that moves lake water to the top of a ramp like chute containing numerous baffles. The water cascades down the ramp and falls back into the lake at a point located as far as possible from the water inlet. Aeration occurs in the cascade chute and in the plunge pool as the water flows away from the ramp.

\subsection{Hypolimnetic System}

This system was developed in an attempt to solve some of the problems inherent in destratification systems, particularly to maintain the cold water layer at the bottom of a lake or reservoir [6]. The technique introduces oxygen to the water at the bottom of the lake without disrupting the thermocline.

There are a few disadvantages when compared with destratification systems. The supply of oxygen to the hypolimnion is relatively slow because of the small surface area available in the aeration apparatus across which the oxygen transfer is made. For water bodies with large hypolimnia or large surface areas, several units must be considered.

Hypolimentic aerators can be further distinguished into two basic groups [6]: full lift and partial lift.

Full lift systems transfer water from the hypolimnium to the surface consequently back to the hypolimnium. This system tends to be less prone to causing nitrogen super saturation in the hyplimnion than the partial lift system.

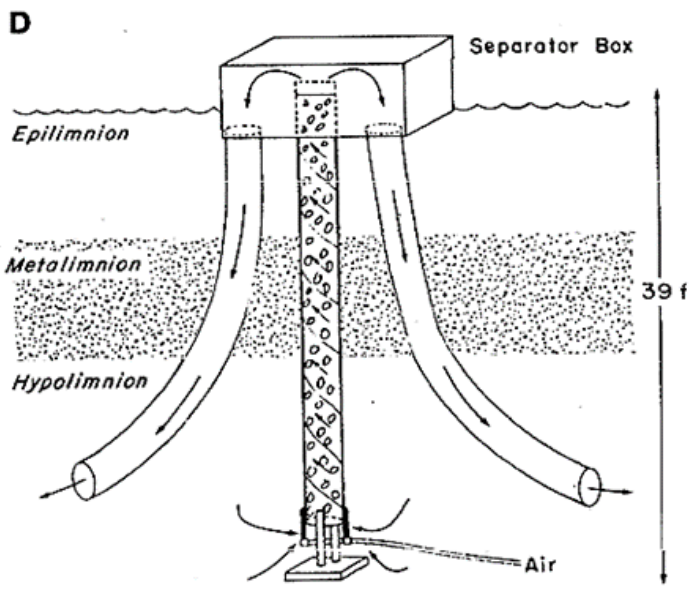

Figure 11. Hypolimentic aeration unit (full lift, [11])

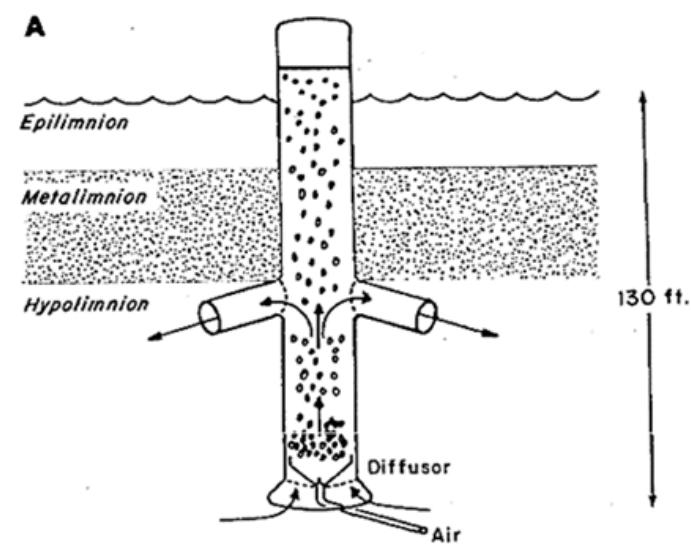

Figure 12. Hypolimentic aeration unit (partial lift, [1])

\subsection{Benefits of Aeration [7]}

- Dissolved oxygen increases to healthy levels

- Stagnation is replaced by a convection current 
- Thermal and Oxygen Stratification are eliminated

- Biological processes start to reduce the muck layer

- Nutrient balance is achieved

- Reductions in algae and weed growth

- Odors are eliminated as an exchange of gasses occurs

- No longer a breeding ground for Mosquito's and Midge Fly's

- Fish habitat is restored

\section{Conclusion}

Aeration systems have been used to improve water quality of lakes and reservoirs. However in some cases no net benefit and even worsening of conditions have occurred because of inappropriate use of aeration systems. Because of this, a detailed evaluation of prevailing chemical and biological limnology and anticipated effects, as well as an engineering evaluation of most appropriate technology is absolutely necessary.

On the other hand, too much oxygen in the water can cause a variety of problems resulting from the water becoming supersaturated [9]. Supersaturated water can cause corrosion (the gradual decomposition of metal surfaces) and sedimentation problems. In addition, air binding occurs when excess oxygen comes out of solution in the filter, resulting in air bubbles which harm both the filtration and backwash process.

Aeration can also cause other problems unrelated to the supersaturated water. Aeration can be a very energyintensive treatment method which can result in overuse of energy [9]. In addition, aeration of water can promote algal growth in the water and can clog filters.

\section{References}

[1] Bernhardt, H., "Impondment destartification by mechanical pumping water quality behavior in reservoir", Public helath Survice publication No. 190, Cincinnati, Ohio. 616 p, 1969.

[2] Boehrer, B., and Schultze, M., "Stratification of lakes”, Reviews of Geophysics, 46(2), RG2005.2008.

[3] Davis, M. L., and Cornwell, D. A., "Introduction to environmental engineering”, (Vol. 3). Landsberg: McGraw-Hill.1998.

[4] Global Climate Change News Brief, "Climate Change Impact on Freshwater Wetlands, Lakes \& Rivers”.2010.

[5] Hakanson, L. and Jansson, M., "Principles of Lake Sedimentology”, Springer-Verlag, Heidelberg, 316 pp.1983.

[6] Nordin, R.N. and McKean, C.J.P., "A Review of lake Aeration as a technique for Water Quality Improvement”, province of British Columbia, Ministry of Environment, Assessment and Planning Division, APD Bulletin 22.1982.

[7] OrganicPond.com. "Oxygen \& Circulation a Key to Pond \& Lake Health”, 33769 Groesbek Hwy Fraser, MI 48026, 888-986-9995. (http://info.organicpond.com/free-aeration-consultation/).

[8] Peavy, H. S., Rowe, D. R., and Tchobanoglous, G., "Environmental engineering", (Vol. 1, No. 9). New York: McGraw-Hill.1985.

[9] Perks, C., "Dealing with stratification within a water supply reservoir", In 69th Annual Water Industry Engineers and Operators' Conference (pp. 30-36).2006.

[10] Riddick, T. M., "Forced circulation of reservoir waters", Water and Sewage Works, 104(6), 231.1957.

[11] Smith, S. A., Knauer, D. R., and Wirth, T. L., "Aeration as a lake management technique", Wisconsin Dept. of Natural Resources Technical bulletin No. 87, Wisconsin Department of Natural Resources, 39 pgs. 1975. (http://digital.library.wisc.edu/1711.dl/EcoNatRes.DNRBull87).

[12] Wetzel, R. G., "Limnology". 743 pp. WB Saunders Co., Philadelphia.1975

[13] Hudson, H. and B. Kirschner. "Lake Notes: Lake Aeration and Circulation”, Illinois Environmental Protection Agency and the Northeastern Illinois Planning Commission. 1997. 